of mesotrons which serve as the chief carriers of the cosmic-ray energy down to the lower levels of the atmosphere.

(3) Bowen's remarkable discovery that atoms, when out in interstellar space, are able to undergo atomic transformations forbidden to them within the stars.

(4) Bowen and Wise's discovery that in ringnebulæ, trillions of miles away from the exciting star and therefore presumably reflecting conditions in interstellar space, there are five of the atoms, namely, helium, carbon, nitrogen, oxygen and silicon, each of which is more than ten times more abundant than any other atom save hydrogen (which must be excluded from measurable cosmic-ray effects because of the smallness of its rest-mass energy).

(5) Lauritsen and Fowler's discovery in the Kellogg Radiation Laboratory that a part, at least, of the rest-mass energy of an atom has the power under suitable conditions of transforming itself directly into the creation of a positive-negative charged-particle pair.

The hypothesis made in view of these five discoveries is that, while the evolution of energy by the stars is maintained, as Bethe has recently shown, by the partial transformation within the stars of the restmass energy of hydrogen into radiant energy through the building of helium, carbon and other atoms out of hydrogen, and the release through this process of the so-called 'packing-fraction' energy, the energy of cosmic rays, on the other hand, is maintained by the occasional complete transformation in interstellar space of the rest-mass energy of the atoms of helium, carbon, nitrogen, oxygen and silicon (and presumably in small amounts of heavier aggregates) into cosmic rays; each such event presumably creating an electron pair, though an occasional photon pair, or even heavier-particle-pair, need not necessarily be excluded.

The foregoing hypothesis requires that the cosmic rays of measurable energy reveal a spectral, distribution of five distinct, definitely measurable bands as follows: (1) a band of rays each having an energy of 1.9 billion electron volts produced by the annihila. tion, or complete transformation, in interstellar space of the rest-mass energy of the helium atom; (2) a carbon-atom-annihilation band of energy $5 \cdot 6$ billion electron volts (b.e.v.); (3) a nitrogen-atom band of energy $6 \cdot 6$ b.e.v. ; (4) an oxygen atom band of energy 7.5 b.e.v., and (5) a silicon atom band of energy 13.2 b.e.v.

The hypothesis requires, further, that there should be in India for vertically incoming rays between the magnetic equator and magnetic latitude about $20^{\circ} \mathrm{N}$. a plateau of unchanging cosmic-ray intensity with latitude. This plateau our experiments in India in 1939-40 brought to light, also the appearance between Agra (17.3 ${ }^{\circ}$ N. Mag.) and Peshawar (25 ${ }^{\circ}$ N. Mag.) of a new cosmic-ray band which we identified with the silicon band of energy $13 \cdot 2$ b.e.v. These results have already been reported ${ }^{2}$, and in that report we promised further tests of the hypothesis in Mexico and the United States. In spite of our absorption in warwork we succeeded in December 1941 and March 1942 in making these tests with the following results, which are reported in full in the Physical Review of April 1-15, 1943.

(1) Tests in Mexico. We had predicted that since the hypothetical silicon-annihilation rays should have enough energy $(13.2$ b.e.v. $)$ to get vertically through the earth's magnetic field at the equator in Peru, though not in India, there should be found, both at sea-level and at all altitudes in the Americas, when vertically incoming rays alone are under test, a very long plateau of uniform cosmic-ray intensities extending north from Mollendo, Peru, to about the latitude of Victoria, Mexico (mag. lat. $32 \cdot 8^{\circ}$ ). There the strong band due to oxygen-annihilation rays $(7.5$ b.e.v. $)$ should first appear, to be followed in going still farther north when the latitude of $40^{\circ} \mathrm{N}$. magnetic had been reached, by the full entrance of the nitrogen-annihilation band $(6 \cdot 5$ b.e.v.). The experimental findings were in accord with these predictions.

(2) Tests in the United States. In going from Pasadena (mag. lat. $40 \cdot 7^{\circ}$ ) to St. George, Utah, but $4 \cdot 1^{\circ}$ (280 miles) nearer to the north magnetic pole than Pasadena, the carbon-annihilation band $(5 \cdot 6$ b.e.v.) was expected to appear, to be followed by a flat plateau clear up to latitude $54^{\circ} \mathrm{N}$. magnetic, when helium-annihilation rays ( $\mathrm{I} \cdot 88$ b.e.v.) were expected to appear. A balloon flight at St. George (mag. lat. $44 \cdot 8^{\circ}$ ) and another at Pocatello, Idaho (mag. lat. $51^{\circ}$ ) yielded preliminary results in harmony with these predictions.

(3) Evidence that the act of atom-annihilation actually transforms the rest-mass energy of an atom into an electron wair. The flat plateau between St. George and Pocatello (mag. lat. $51^{\circ}$ ) corresponding to the absence of abundant atoms of atomic weight between that of carbon and that of helium, and the definite appearance of a new band between Omaha (mag. lat. $51 \cdot 3^{\circ}$ ) and Bismarck (mag. lat. $56^{\circ}$ ), constitute new and strong evidence for the transformability of the complete rest-mass energy of an atom into an electron pair.

'Phys. Rev., 53, 217 (1938) and 61, 397 (1942).

${ }^{2}$ Phys. Rev., B1, 397 (1942).

\section{SIR DAVID GILL, K.C.B., F.R.S., I843-1907}

\section{By ENG.-CAPT. EDGAR C. SMITH, O.B.E., R.N.}

UNE 12 is the centenary of the birth of Sir David Gill, who has been called "the greatest Scottish astronomer of his generation". Borm in Aberdeen and educated at the University there, where he came under the influence of Maxwell, he early abandoned a lucrative business career for the life of an astronomer, and eventually gained a world-wide reputation among his fellows.

Gill made his first observations in the small observatory at King's College, Aberdeen ; afterwards he erected a reflector in the garden of his father's house, and then in 1872, at the age of twentynine, became the first director of the Dunecht Observatory erected by Lord Lindsay, afterwards the Earl of Crawford. In 1874 he organized and accompanied Lord Lindsay's expedition to Mauritius to observe the Transit of Venus. His next expedition was to Ascension, which he visited in 1877 with the object of determining the solar parallax from measures of the parallax of Mars at its nearest to the earth.

His work during these expeditions was so notable that in 1879 Gill was appointed to succeed E. J. Stone as "Her Majesty's Astronomer" at the Cape of Good Hope. This position he held until 1906, raising the reputation of the Observatory and playing a part in many important undertakings. A successful photograph of the great comet of 1882 suggested to him the practicability of mapping the whole sky, resulting ultimately in the inauguration of the great 
International Astrographic Chart and Catalogue at the Paris Congress of 1887. Of this work Gill said in 1907: "A century hence this great work will have to be repeated, and then, if we of the present day have done our duty thoroughly, our successors will have the data for an infinitely more complete and thorough discussion of the motions of the sidereal system than any that can be attempted to-day".

Another scheme of Gill's was the measurement of the Great African arc on the 30th meridian. So early as 1874, after his visit to Mauritius, at the invitation of General Stone, chief of the military staff of the Khedive, he had measured a base-line for a proposed survey of Egypt, and once settled at the Cape he took up the question of a geodetic survey of South Africa. It became the dream of his life to see the completion of the measurement of an arc from Cape Agulhas to Cairo, whence the measurement would be carried by the eastern shore of the Mediterranean and Greece to meet Struve's great are which extends to North Cape.

But while it was these and other labours of a kindred nature which occupied Gill's time and raised him to a leading position in the astronomical world, his success was to a large extent due to his simple, direct and energetic character. As his biographer in the Report of the Council of the Royal Astronomical Society for 1915 said : "Those who came in contact with him felt the charm of his personality. In some indefinable way he could inspire others with his enthusiasm and determination. Enjoying a life crowded with activity, surrounded by an unusually wide circle of friends, he was ever ready and eager to encourage the humblest beginner." Settling in London after his retirement from the Cape, he did valuable service for various scientific societies, and in 1913 he published his "History and Description of the Cape Observatory".

Gill was elected a fellow of the Royal Society in 1883 and made K.C.B. in 1900 . He fell ill with pneumonia in December 1913, and died on January 24, 1914; he was buried at Aberdeen.

\section{OBITUARIES}

\section{Mr, Lionel R. Crawshay}

Mr. L. R. Crawshay, who died suddenly at Plymouth on April 24, was born at Honiton on July 9, 1868. ' He was educated at Harrow and Brasenose College, Oxford; he graduated in arts, but later took up natural science, studying under Prof. Minchin at University College during 1903-5. He was then appointed assistant naturalist to the Marine Biological Association under Dr. E. J. Allen, a post which he held until 1914. During the War of 1914-18 he served as a trooper in the First King Edward's Horse and as instructor in computation, Field Survey Co., R.E. In 1919 he was awarded a Ray Lankester investigatorship at the Plymouth Laboratory, but shortly afterwards he was selected for a Colonial Office appointment as research officer, Sponge Fishery Investigations. The post was a temporary one, at Nassau in the Bahamas, and was originally for one year only; but Crawshay quickly proved his capacity and the appointment was repeatedly extended until his service had reached a total of fifteen years. He worked for some time in British Honduras, living in primitive conditions on a reef adjacent to the sponge fisheries, and in 1930 he was deputed to report on the sponge industry in Cyprus. $\mathrm{He}$ retired in 1934, and during the remainder of his life he worked regularly at the Plymouth Laboratory, continuing his researches on the Porifera with unabated enthusiasm.

It is greatly to be regretted that so little of Crawshay's unrivalled knowledge of sponges and sponge culture has been published. The results of his long years of work in the West Indies and British Honduras were sent as official reports to the Colonial Office and none of them has been printed. His report on the Cyprus industry has, however, been published, and one paper, intended as the first of a series, which he wrote after his retirement. Throughout his life he was interested in entomology, in which his brother, the Rev. G. R. Crawshay, did most useful work; in 1903 he published a detailed account of the development of Drilus (Coleoptera) and he made valuable observations (not published because he regarded them as incomplete) on certain Dartmoor Coleoptera. He wrote on the arterial system of the Anura, contributed short papers on a variety of subjects to the Journal of the Marine Biological Association, and reported on the microplankton obtained by the Scotia in a voyage which he himself accompanied in 1913.

Crawshay was a keen lover of Nature at its wildest. $\mathrm{He}$ delighted in solitary tramps across the remotest parts of Dartmoor, and spoke with such enthusiasm of his work abroad that it may be doubted whether he ever felt the extreme loneliness of his life on the sponge lagoons. As a scientific worker he had outstanding qualities, observing and recording with scrupulous accuracy and exercising the greatest caution in his deductions. $\mathrm{He}$ devoted himself to his work to the exclusion of every other thought, and had no regard whatever for his own material comforts. To all at the Plymouth Laboratory he endeared himself by his modesty and charm of manner and by his constant thoughtfulness for others.

S. KEMP.

\section{Dr. H. Gordon Rule}

Dr. H. Gordon RuLE, reader in the Department of Chemistry at the University of Edinburgh, died on March 15, at the age of fifty-five. After graduating with honours in chemistry at Birkbeck College, London, he carried out research with Prof. Alex McKenzie and then worked for two years under Otto Dimroth in von Baeyer's laboratory in Munich, where he gained his Ph.D. in 1912. Returning to Great Britain, Rule spent a year at Birkbeck College and in 1913 went as an assistant to the University of Edinburgh. In 1921 he was appointed senior lecturer in organic chemistry, a position he held until his death. $\mathrm{He}$ was made reader in 1939.

Much of Rule's time was devoted to research, but he never neglected his teaching duties. He was an excellent teacher and his lectures were models of clearness and conciseness, while his quiet humour added to his popularity with the students. It was the same at the Chemistry Colloquium: a 'full house' was assured if Rule was the speaker.

Rule's main research work extended over a period of twenty years and dealt with the factors governing the magnitude of optical rotatory power, a problem which had earlier attracted the attention of another Edinburgh chemist, Crum Brown. Rule published more than thirty papers on this subject and estab- 